\title{
Home-Based Networks, Local Institutions and Innovation of Chinese Multinational Firms
}

\author{
Xiaoyu $\mathrm{Wu}^{*}$, Veronica Hoi in Fong \\ School of Business \\ Macau University of Science and Technology \\ Macau, China \\ xywu@must.edu.mo*, hifong@must.edu.mo
}

\author{
Jacky Fok Loi Hong \\ Faculty of Business Administration, \\ University of Macau \\ Macau, China \\ fbaflh@umac.mo
}

\begin{abstract}
This paper contributes to the literature of innovation, network strategies and institutions in emerging China by identifying the bridging role of home-based networks between different indigenous institutions and innovation of Chinese firms. Focusing on the mediating function of home-based networks, we advance three arguments. First, the needs of consolidating and integrating knowledge on home-based networks significantly improve our understanding of innovative capabilities of contemporary Chinese firms. Second, the exploitative and explorative home-based networks are defined as the salient idiosyncrasies in China that help Chinese firms to gain their competitive advantages under the boundary of different institutions. Lastly, defining the specific normative and cognitive institutions in China fosters our understandings of the facilitating factors for the formation of home-based networks, which the extant literature has largely ignored.
\end{abstract}

Keywords-Exploitative home-based network; Explorative home-based network; Institutional environment; Innovation

\section{INTRODUCTION}

It is widely believed that the economic and enterprise reforms have significantly improved the development, diffusion and implementation of technological innovation in Chinese firms. The transition period in the last two decades has turned China into a "workshop for the world," a vehicle for Western firms to exploit their technological and managerial knowledge; and Chinese firms are innovating as a result of "knowledge spillover" [1]. The transformation of the Chinese economic system from a centrally planned to a free market economy has had great impact on the Chinese innovation system, which in turn has led to major changes in both the nature and patterns of Chinese firms' innovation activities.

China provides an interesting setting for studying innovation. For a long period of time, China had a poor record in technological innovation when compared with the developed countries. But since the mid-1990s, it has been an important location for research and development (R\&D) and innovative activities by domestic enterprises. The extent of R\&D and other knowledge-intensive activities conducted by different business enterprises is increasing sharply and its impressive record of inbound foreign direct investment (FDI) greatly affects indigenous innovation.

In a developing country like China, tapping into the knowledge stock from foreign partners appears as a vital way of bridging the technology gaps, and it is arguably more efficient than trying to advance the domestic technology frontier through indigenous R\&D efforts alone. Research on innovation had initially been confined to developed countries. However, the interactions between institutional environment and the strategic responses from local firms through the formation of home-based networks that contribute to various innovative capabilities are largely ignored in those studies. In this paper, we are going to examine the co-evolution of the institutional environment and home-based networks in China, as well as their possible effects on the innovative capabilities of Chinese firms. We are particularly interested in three questions that appear to drive firm-level innovative capabilities in China: (i) What determines the variations in innovative capabilities across enterprises? (ii) How can the home-based networks be used as strategic tools for mediating the influence from local institutions and promoting innovative capabilities? (iii) What are the motives for the formation of home-based networks and the corresponding impact on innovative capabilities?

\section{Theoretical DeVelopment}

The transformation of the Chinese economic system from a centrally planned to a free market economy has had a great impact on the Chinese innovation system [2] which, in turn, has led to major changes in both the nature and patterns of Chinese firms' innovation activities.

\section{A. Home-based Networks in China}

Based on Nelson's [3] evolutionary approach to economic growth, one sees China's transition from an economy in which growth is based on labor-intensive production and imported ideas and technology, to one in which growth is largely driven by domestic innovation. It is expected that institutions and firms will take up different roles by promoting advanced technology and developing new capabilities and technologies in China. The most significant role of networks is the linkage or connection for external markets, and this argument is supported by several empirical studies on the innovation of Chinese firms. Narula [4] defines two types of home-based knowledge networks in the Chinese context: links to government and other domestic companies, and links to foreign companies in China. Here, we classify networks into exploitative home-based networks and explorative home-based networks.

Exploitative home-based network: By fostering partnerships with government and both domestic firms and

This work was supported by the Macau Foundation. 
foreign entrants in the home country markets, these network assets are typically utilized to exploit existing certainties which include such things as refinement, choice, production, efficiency, selection, implementation, and execution. The key proposition for forming this exploitative home-based network is the performance impact of innovation by obtaining all sorts of existing resources and capabilities, and developing business connections not otherwise available.

Explorative home-based network: By fostering partners with foreign firms in the home country markets in innovative ways, firms have been able to achieve accelerated innovation through both organizational and technological innovations of new possibilities, which include a process of creative search, variation, risk taking, experimentation, flexibility, and discovery. These innovations are a driving force to obtain success that is well adapted to the circumstances of the emergent global economy.

\section{B. Institutional Environment in China}

According to institutional theory, organizational environments are conceptualized as "fields" in which interacting organizations are constrained by regulative, normative, and cognitive structures. Regulative, normative, and cultural-cognitive systems have been identified by Scott [5] as the conceptual pillars of institutions. The three facets can be viewed in both interdependent and mutually reinforcing ways, moving from the conscious to the unconscious, and from the legally enforced to the taken for granted. They are structures and activities typically viewed as both imposing constraints and enacting enablers that provide stability and meaning to social behavior. There are many examples of institutions providing enabling functions. Starting from early 1990, the Chinese OFDI has been strongly supported by the Chinese government through various regulations, such as supporting exports, providing resource supply, and acquiring technology [6].

\section{Impact of Instituions on the Innovation Capabilities}

A firm's strategic choices are fundamentally influenced by both formal and informal institutions domestically [7]. Given the extent of government control, the Chinese institutional environment is likely to have dramatic effects on developing innovation capabilities. The general approach of gradual reforms and transformation is seen in the liberalization model adopted by China where state-owned enterprises continue to play an important role. However, organizational transformation in a market-based regime is accomplished through accessing external resources by inter-organizational collaborations and changes in intra-organizational norms and culture. Accordingly, institutional theory has been predominantly used to explore how Chinese home country institutions function - particularly the role of the Chinese government acting through different driving forces and barriers of innovation capabilities. According to [5], three main institutions are discussed here. They are regulative, normative and cultural-cognitive institutions.

- Regulative institutions
Regulative institutions engage in rule-setting, monitoring, and sanctioning activities. In this conception, regulatory processes involve the capacity to establish rules, inspect others' conformity to them, and, as necessary, manipulate sanctionsrewards or punishment - in an attempt to influence further behaviour. These processes may operate through diffused and informal mechanisms, involving folkways such as shaming or shunning activities; or they may be formalized and assigned to specialized actors, such as police and courts. Regulative institutions also are involved with resources control, where state or local government maintains full control over the redistribution of capital and important raw materials.

\section{- Normative institutions}

Normative institutions represent the prescriptive, evaluative, and obligatory dimension of social life. A normative system includes both values and norms. Values are conceptions of the preferred or the desirable, together with standards to which existing structures or behaviors can be compared and assessed. Norms are specific about how things should be done; they define legitimate means to pursue valued ends. The normative institution defines goals and objectives and designates appropriate ways to pursue them. It also involves reciprocitybao (or pao) in Chinese - which is cited as the basis for social relations in China. Bao has complex and multiple meanings in Chinese, but centers on the notions of response and return. It refers not only to interpersonal exchange, but to the "restoration of moral and ritual equilibrium" [8]. Yang [9] states that Chinese believe that "the reciprocity of actions... should be as certain as a cause-effect relationship, and, therefore, when a Chinese acts, he normally anticipates a response or return." He also notes that whilst the notion of reciprocity is evident in all societies, in Chinese society it has particularly "wide application and tremendous influence in social institutions" [9]. In the Confucian Book of Rites, reciprocity is an integral part of propriety (li).

\section{- Cognitive institutions}

Cognitive institutions embody the shared conceptions that constitute the nature of social reality and the frames through which meaning is made. Cognitive dimensions mediating between the external world of stimuli and the response of the individual organism are a collection of internalized symbolic representations of the world. A cognitive institution is made of Guanxi, which refers to the state of two or more parties being connected, or the connected parties themselves. It can be two individuals or an organization, functioning as a dyad or as network. Guanxi can be fundamentally explained by its historical and cultural roots in Confucianism. The importance of Chinese human relationships can be further explained by using wu lun. Modern Chinese society remains very much relationship-oriented based on wu-lun [10]. The current perspective on guanxi discerns three types, depending on the basis of relationship: family ties (kinship), familiar persons (e.g., classmates and colleagues), and strangers (with or without common demographic attributes). Such relationships are perceived according to the social order and people's position in it. 


\section{CONCEPTUAL FRAMEWORK}

\section{A. Institutions and Home-based Networks}

1) Resource control and exploitative home-based networks: The monopoly control of resources by the government directly affects the extent of firms' performance. Some scarce resources, such as land, capital, raw materials, licensing for business entry and exits, subsidies and tax arrears, and other relevant business information are still heavily depend on the supply of government; especially as it has monopoly control over two production input factors vital to any business-land and business credits. It is not surprising to find that private firms are often left out of business opportunities due to a lack of resources, even if their products are popular in the market. Their survival depends on unreliable market rules of the game set by the government. Facing insufficient market factors, they have to build a close network with the government and other business partners who can provide sufficient resources and capabilities owned by others.

P1: As a regulative institutional constraint, resource control has a positive effect on the formation of exploitative homebased networks in China.

2) Reciprocity and exploitative home-based networks: Reciprocity is deeply embedded in Chinese social relations and the constituted moral order. It is central to li and so is the key tenet of proper and effective behaviour. It is inherent to all relationships and is not just a calculated expedient, but a moral imperative governing proper behavior in all situations and relationships. Chinese elemental relationship orientation entails that there is mutual interdependence in all relationships, even in unequal relationships where the more powerful not only has rights, but also obligations. The rule of propriety, and particularly of bao, demands and ensures this mutuality of obligation - a moral imperative in a complex social ethic. Chen and Chen [11] explain that reciprocity operates on dynamic and operating principles. In China, reciprocity of favor exchanges is the most pervasive rule guiding Chinese social and economic interactions. It emphasizes a long-term orientation; that is, the response or return need not (and in most cases should not) always be immediate. Reciprocity in China is indeed of great value to the receiver. The other type of reciprocity requires greater knowledge of and concern for others' needs and well-being. However, reciprocity can be an unequal exchange, in which "both sides will practice trying to do more, improving with every new effort, in a system of escalating favors" [12]. In China, firms seek resources and support through relationship building based on managers' personal trust and personal ties. A manager's personal value of reciprocity is, to a great extent, the organizational value of reciprocity, which has a strong influence on the nurturing, building and developing of a network.

P2: As a normative institutional enabling factor, reciprocity has a positive effect on the formation of exploitative homebased networks in China.

3) Guanxi and exploitative home-based networks: In China, people develop networks through the guanxi bases.
Personal relationship can be based on different types of guanxi: (1) common social identities related to the birthplace (tong xiang), educational institution (tong xue), and workplace (tong shi ); (2) "common third-party" ties, which refers to two unknown individuals who can develop guanxi through the presence of a third party for the purpose of obtaining help, resolving problems or simply getting connected; (3) anticipatory bases. which refers to chances for future exchanges, collaborations, or joint ventures even when people are not well acquainted. This is mainly caused by the increase of marketization of the Chinese economy and the mobility of contemporary Chinese society. Due to the egocentric nature of the Chinese guanxi network, guanxi quality can be assessed by the distance between the partners. The closer the partners in the guanxi network, the better the guanxi they maintain. Besides, Chinese normally assess guanxi quality through the familiarization between parties, which mainly relies on trust, feeling and long-term orientation. Alston [13] examines guanxi at the network level and identifies its function in maintaining social order and substituting where the legal system cannot be reached. The importance of networks of these interpersonal relationships is rooted in guanxi, which has been the lifeblood of personal relationships and business conduct in Chinese society. In China, guanxi helps a firm overcome the lack of different resources. As a loosely structured network, guanxi is an efficient mechanism to facilitate economic exchanges and to overcome administrative interventions. Some studies have indicated that a primary concern of Chinese managers and organizations is to engage in extensive networking activities through guanxi and various informal agreements to build trust and exchange favors.

P3a: As a cognitive institutional facilitator, guanxi has a positive effect on the formation of exploitative home-based networks in China.

P3b: As a cognitive institutional facilitator, guanxi has a positive effect on the formation of explorative home-based networks in China.

\section{B. Relationship Between Exploitative and Explorative Home- Based Networks}

Research on strategic networking [14] has long suggested the need for learning and is a major rationale for network formation. Exploitation and exploration require substantially different structures, processes, strategies, capabilities, and cultures to pursue and may have different impacts on firm adaptation and performance. Exploitative home-based networks enable Chinese firms to acquire their existing possibilities provided by their business partners and governments. These possibilities include the benefits to associate with mechanistic structures, tightly coupled systems, path dependence, routinization, control and bureaucracy and stable markets and technologies. Relying on these, Chinese firms are able to upgrade their existing knowledge. In addition, because of these, Chinese firms are capable of exploring new technology, R\&D and innovations through the network provided by the foreign entrants in China. In other words, exploitative home-based networks allow Chinese firms to 
move from resource seeking to leveraging and learning through the channel of explorative home-based networks.

P4: Relying on the existing resources and capabilities provided by exploitative home-based networks, Chinese firms are able to upgrade themselves and generate new knowledge and innovation when they socialize with the explorative homebased networks.

\section{Home-based Networks and Innovation Capabilities}

1) Exploitative home-based network and technological innovation capabilities: Exploitative home-based networks increase Chinese firms' tendency to engage in technological innovation capabilities through the government and with different partners' financial support, market information and resources supply. Firms belonging to the same business network can gain precious information and experience from peer members in China. Motohashi and Yuan [15] prove that local firms have spillover effects from vertical innovative activities and that the vertical spillover from the local firms is stronger. Especially, domestic partners who have already adopted foreign technologies may serve as a bridging role and help narrow the innovation gap. Their ties with other domestic firms that have already adopted foreign technologies could be important in reducing different innovative constraints. Besides, the network built with the government-supported institutions that may have access to information about foreign technologies could also be effective to Chinese MNEs' innovation capabilities. The exploitative home-based network established with other business partners or government officials ensures that Chinese firms can access resources that can assist them to further develop their innovation capabilities.

P5: Exploitative home-based networks increase the tendency of Chinese firms to develop innovation capabilities.

2) Explorative home-based networks and technological innovation capabilities: Inbound FDI is a package of capital, technology and managerial skills, and is viewed as an important source of both direct and indirect knowledge spillover. The strongest channel for diffusing knowledge and technology from foreign affiliates is the network they establish with local firms and institutions [16]. Inbound FDI provides local firms with sufficient learning opportunities and enables them to search and access valuable information that is not provided at home. Domestic firms that have network ties to foreign firms, compared with those without, are better positioned to search and benefit from transfer of foreign technologies; thus they are more likely to benefit from FDI spillover. Through new innovations and knowledge extracted from the foreign entrants in local markets, Chinese firms can overcome their competitive disadvantage by leveraging these exploration processes to engage in more innovation activities. A key factor determining the benefits that host countries can derive form FDI is the networks that foreign affiliates establish with indigenous firms [17]. So, from the lens of insiders operating with the outsiders in China, local MNEs could benefit by accessing the brokering opportunities of home-based networks with the network ties developed by foreign firms in their home markets. Under this situation, home-based networks serve as a strategic platform which enables Chinese firms to develop innovation capabilities through their possession of foreign spillover knowledge, and to explore distant markets in terms of (1) various tangible and intangible assets of foreign market opportunities; (2) advice and experiential knowledge; and (3) referral trust and solidarity by a third business partner abroad. As a whole, these learning opportunities enhance Chinese firms' international knowledge and opportunities and provide a rich network source for relationship building between local and foreign business, which facilitates Chinese firms to explore more innovation capabilities.

P6: Explorative home-based networks increase the tendency of Chinese firms to develop innovation capabilities.

\section{CONCLUSION}

In this paper, we define different functions of home-based networks between Chinese institutions and innovation capabilities of Chinese firms. First, we distinguish two different types of home-based networks and their impact on Chinese firms' innovation capabilities. Second, the key factors underlying each institutional force are identified and their impacts on the formation of home-based networks in China are discussed. There are three theoretical contributions. First, innovation capabilities of Chinese firms have attracted attention from scholars over the past few years. Although a number of studies have explored the impact of institutional environment on the development of innovation capabilities, most simply review the direct relationship between institutions and innovation capabilities. Some other mediators or moderators are somewhat neglected. The present study reviews the mediating role of home-based networks between the three institutional pillars and innovation capabilities of Chinese firms. Second, the home-based network is a novel concept. The exploitative and explorative home-based networks proposed in this study provide a newly unified framework for explaining the rise of emergent market MNEs, which use the strategic intent to exploit their competitive advantages [18]. A homebased network is defined as one of the salient idiosyncrasies that serves as a precursor for innovation capabilities and helps firms to secure their competitive advantages in the domestic market. The advantages are largely dependent on the improvements of firms' existing market networks of both types, exploitation and exploration. Third, specific institutional factors in China and their influence on home-based network formation are defined. Within China, a majority of institutional studies examine Chinese governmental characteristics in explaining the innovative national system, and their effect on developing industry or firm level innovation capabilities. Defining the factors of normative and cognitive institutions has fostered our understanding of the formation of home-based networks in the current study. 


\section{REFERENCES}

[1] X. Liu and T. Buck, "Innovation performance and channels for international technology spillovers: Evidence from Chinese high-tech industries," Research Policy, vol. 36(3), pp. 355-366, 2007.

[2] R.P. Suttmeier, C. Cao, and D.F. Simon, "China's innovation challenge and the remaking of the Chinese academy of sciences," Innovations, vol. 1(3), pp. 78-79, 2006

[3] R.R. Nelson and S.G. Winter, An evolutionary theory of economic change, Harward University Press, Cambridge, MA, 1982.

[4] R. Narula, "The Modern MNE as an efficient meta-integrator: Emerging market MNEs need to foster internal embeddedness to succeed., John $\mathrm{H}$ Dunning Center for International Busisness Discussion Papers jhd-dp 2016-02, UK, 2016

[5] W.R. Scott, Institutions and organizations: Ideas and interests, 3rd ed., Sage Publications, 2007.

[6] K.G. Cai, "Outward foreign direct investment: A novel dimension of China's integration into the regional and global economy," China Quarterly, vol. 160, pp. 856-880, 1999.

[7] M. Wright, I. Filatotchev, R.E. Hoskisson and M.W. Peng, "Strategy research in emerging economies: Challenging the conventional wisdom," Journal of Management Studies, vol. 42(1), pp. 1-33, 2008.

[8] R.F. Company, Strange writing: Anomaly accounts in early medieval China, Albany, State University of New York Press, 1996.

[9] L.S. Yang, The concept of Pao as a basis for Chinese thought and institututions, Chicago,University of Chicago Press, 1957.
[10] G. Redding and G.Y.Y Wong, The psychology of Chinese organizational behavior, In M.H. Bond (Ed), The psychology of the Chinese people, New York, Oxford University Press, 1986, pp. 213-266

[11] X.P. Chen and C.C. Chen, "On the intricaacies of the Chinese Guanxi: A process model of Guanxi development," Asia Pacific Journal of Management, vol. 21(3), pp. 305-324, 2004.

[12] C. Hampden-Turner and F. Trompenaars, "Mastering the infinite game: How east asia values are transforming business practices," Capstone Publishing Limited, Oxford, England, 1997.

[13] J. Alston, "Wa, Guanxi, and Inwa: Managerial principles in Japan, China, and Korea," Business Horizons (3), pp. 26-31,1989.

[14] R. Gulati, N. Nohria, and A. Zaheer, "Strategic network," Strategic Management Journal, vol. 21, pp. 203-216, 2000.

[15] K. Motohashi and Y. Yuan, "Productivity impact of technology spillover from multinationals to local firms: Comparing China's automoble and electronics industries," Research Policy, vol. 39(6), pp. 790-798, 2010.

[16] X. Liu, C. Wang, and Y. Wei, "Do local manufacturing firms benefit from transactional linkages with multinational enterprises in China," Journal of International Business Studies, vol. 40(7), pp.1113-1130, 2009.

[17] UNCTAD, World investment report: Transnational corporation, agricultural production and development, New York and Geneva, United Nation Publication, 2009.

[18] Y. Luo and R.L. Tung, "International expansion of emerging market enterprises: A springboard perspective," Journal of International Business Studies, vol. 38(4), pp.481-498, 2007. 